\title{
Effect of neighboring-microstructure on the rolling contact fatigue around non-metallic inclusion
}

\author{
Izumi Shimoji*, Masahide Natori, Hideyuki Hidaka, and Yuji Miyamoto \\ NSK Ltd., Core Technology R\&D center, Fujisawa, Kanagawa, Japan
}

\begin{abstract}
It is well known that the flaking of a raceway causes the bearing failure, and the flaking mechanism depends on the lubrication condition. In the case of ideal lubrication condition with sufficient oil film thickness, the flaking originates from a non-metallic inclusion at the subsurface. It occurs through the formation of butterfly structure due to stress concentration around the inclusion. Therefore, the countermeasure of this type of flaking is to make cleaner steel by the reduction of inclusions. However, further reduction of inclusion imposes an extra challenge for the current steel making process. Therefore, in this paper, the effect of neighbouring microstructure on the butterfly structure is evaluated to propose a new life improvement method for rolling contact fatigue. It was suggested that it's important to eliminate strain localization near inclusion for improving bearing life.
\end{abstract}

\section{Introduction}

Rolling bearing is a machine element that supports the smooth rotation of a shaft, even under a heavy load and high speed rotation. The bearing ring and rolling element has a line or point contact, which induces a high compressive stress because of the small contact area. This causes the flaking of a raceway which limits the bearing life.

The bearing raceway can have flaking from various reasons, which mostly depend on the lubrication condition. Therefore, the bearings are recommended to be used under a good lubrication condition with a sufficient oil film thickness and clean oil. In this case, however, the flaking is caused by the crack originated from the subsurface inclusion. Hence, the life of the bearing is basically considered to be dependent on the size, position, and amount of nonmetallic inclusion.

The previous studies have shown that the fatigued microstructure neighboring to an inclusion is a butterflyshaped structure [1,2]. The crack originates from the boundary between the butterfly structure and matrix, and propagate to the surface which results in flaking. The butterfly structure is formed by the microstructural changes occurred due to the nanocrystallization of matrix and decomposition of cementite under the Rolling-Contact Fatigue (RCF) stress [3]. It is believed that these microstructural changes is caused by the stress concentration around the inclusion. At present, the way to improve the bearing life is to use cleaner steel with reduced amount and smaller size of inclusion.

On the other hand, the cleanliness of steel is saturated to its maximum level and further reduction of inclusion imposes an extra challenge for the current steel making process. The author aimed to reduce the harmful effects of the inclusions by focusing on the reduction of butterfly structure formation. In order to achieve this, the factors affecting the formation of the butterfly structure are probed in detail.

The butterfly structure formation is suggested to be caused by the strain localization due to the stress concentration around the inclusion [4]. Therefore, a homogenous strain distribution in neighbouring microstructure can have a tendency to limit its formation. In order to inhibit the strain localization, average stress should be high enough to widely deform the surrounding regions of an inclusion. From this viewpoint, the increment of applied stress or decreasing the hardness of the material can have a possiblity to reduce the butterfly structure formation and consequently, can improve the bearing life.

In this research, we investigated the influence of the load condition and the initial hardness on the butterfly structure formation. The influence is evaluated by focusing on the strain distribution on the surrounding microstructure of inclusion in order to avoid the strain localization.

\section{Experimental methods}

The material used for this study was a bearing steel with a large amount of nonmetallic inclusions. A 6206 deep groove ball bearing was used, in which the hardness was adjusted for $735 \mathrm{HV}$ and $600 \mathrm{HV}$ by tempering at different conditions. The bearing was tested for RCF life under an ideal lubrication environment. The rotational speed was set to $3900 \mathrm{~min}^{-1}$. The bearing was tested under the radial test load of $635 \mathrm{kgf}$ and $1410 \mathrm{kgf}$. Therefore, there were three types of test conditions (a) standard test: $735 \mathrm{HV}$ specimen with a radial test load Fr

*Corresponding author: shimoji-i@nsk.com 
$=635 \mathrm{~kg}$, (b) heavy load: $735 \mathrm{HV}$ specimen with a radial test load $\mathrm{Fr}=1410 \mathrm{~kg}$ and (c) soft microstructure: 600 $\mathrm{HV}$ specimen with a radial test load $\mathrm{Fr}=1410 \mathrm{kgf}$.

The bearing test was stopped whenever there was flaking of inner or outer raceway. The test was also suspended at arbitrary time durations. The microstructural observation was done on the crosssection along the center of raceway by Optical Microscopy (OM) and Scanning Electron Microscopy (SEM). The sample was cut from the inner bearing ring and the preparation for observation was done by standard techniques of mounting, polishing and chemical etching. The butterfly structures were observed and the number of them was counted by OM on the cross-section area with $7 \mathrm{~mm}$ circumferential width. However, for the case of $600 \mathrm{HV}$ specimen with the load of $1410 \mathrm{kgf}$, the observation area was increased to various cross sections to measure the sufficient number of butterfly structures.

The microstructure was further evaluated by EBSD/OIM analysis for measuring the strain values from the neighboring microstructure around the inclusion. The sample was prepared up to mirror finish by polishing with the colloidal silica. The Inverse Pole Figure (IPF) map and Image Quality (IQ) map were generated to evaluate the fatigued microstructure from the specimen.

\section{Result and discussion}

\subsection{Influence of the radial test load on the formation of butterfly structures}

This section, investigates the influence of an increase in the radial test load on the butterfly structure formation.

Figure 1 shows the frequency distribution of butterfly structures along the depth in the inner ring of a 6206 deep groove ball bearings with hardness of $735 \mathrm{HV}$. A standard radial test load of $635 \mathrm{kgf}$ and a higher test load of $1410 \mathrm{kgf}$ was applied for the RCF life test. The number of butterfly structures was measured at various depths from the raceway surface with $50 \mu \mathrm{m}$ apart.

The formation of the butterfly structure is sometimes uncertain because of inclusion characteristics like size, position and the kinds which affect the surrounding stress state. This makes it difficult to compare the test results. To deal with this probabilistic behavior, the RCF tests were conducted for the various time duration. To evaluate this tendency the frequency of butterfly structure is summed up for the same depth for all test durations.

The dotted line in the figures shows a distribution of dynamic shear stress, which is calculated along the depth for each loading case by considering the Young's modulus of the material. The shear stress value is high for the higher test load of $1410 \mathrm{kgf}$ such that the maximum shear stress value is about 1.3 times than that of $635 \mathrm{kgf}$. The position of maximum shear stress is slightly deeper by about $30 \mu \mathrm{m}$ for $1410 \mathrm{kgf}$.

In case of $635 \mathrm{kgf}$ test load, the frequency distribution of butterfly structure corresponds to the dynamic shear (a) $635 \mathrm{kgf}$

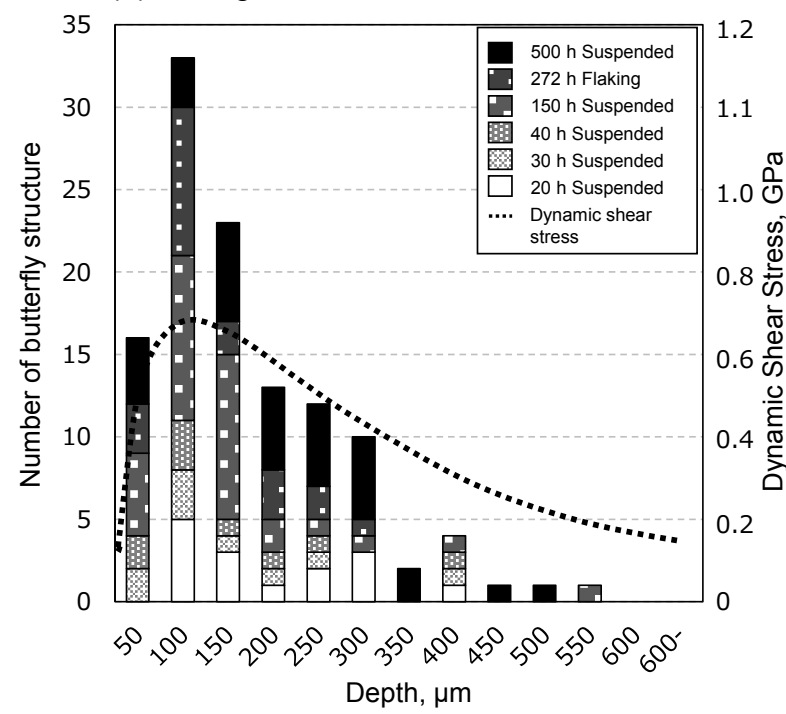

stress distribution. The higher frequency of butterfly

(b) $1410 \mathrm{kgf}$

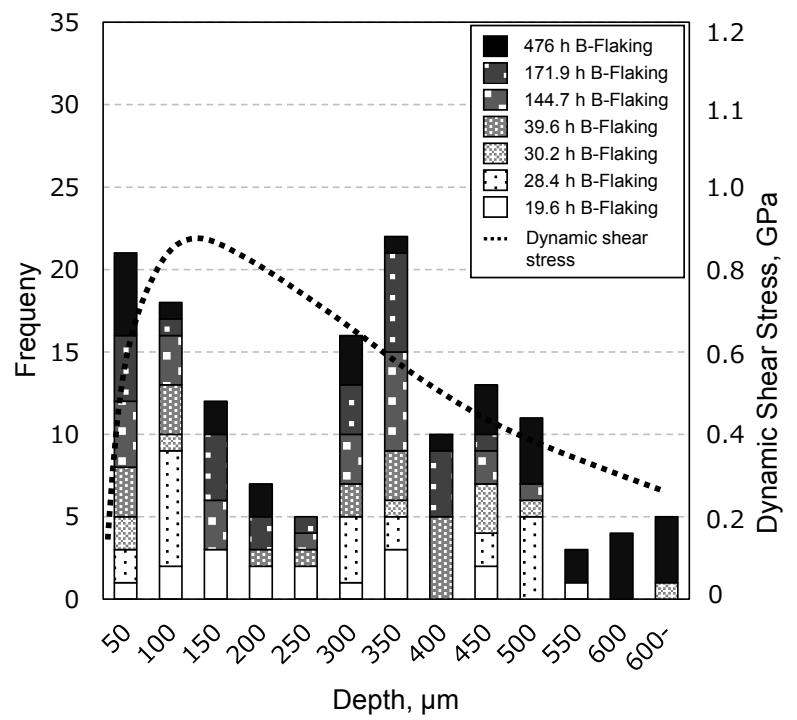

structure occurs at the depth of maximum shear stress. On the other hand, in case of $1410 \mathrm{kgf}$ test load, the frequency distribution of butterfly structure does not correspond to

Fig.1. Frequency distribution of the butterfly structure formed along the depth in the inner ring of a 6206 deep groove ball bearing with hardness of $735 \mathrm{HV}$ under RCF testing load of (a) $635 \mathrm{kgf}$ and (b) $1410 \mathrm{kgf}$.

the dynamic shear stress.

Figure 2 shows the size distribution of butterfly structure along the depth of the inner ring. The size is described only by considering the length of the butterfly structure. The size distribution belongs to same butterfly structures of specimens, whose frequency is shown in fig. 1. In case of $635 \mathrm{kgf}$ test load, the size distribution well corresponds to the dynamic shear stress. On the other hand, in case of $1410 \mathrm{kgf}$ test load, the size of it decreases at the higher shear stress depth. These tendencies are almost similar to the frequency distribution in each load condition. 
These results show that the generation of butterfly structure is reduced at the depth of the higher shear stress. This indicates that there is another factor except for the stress. To investigate this phenomenon, further

(a) $635 \mathrm{kgf}$

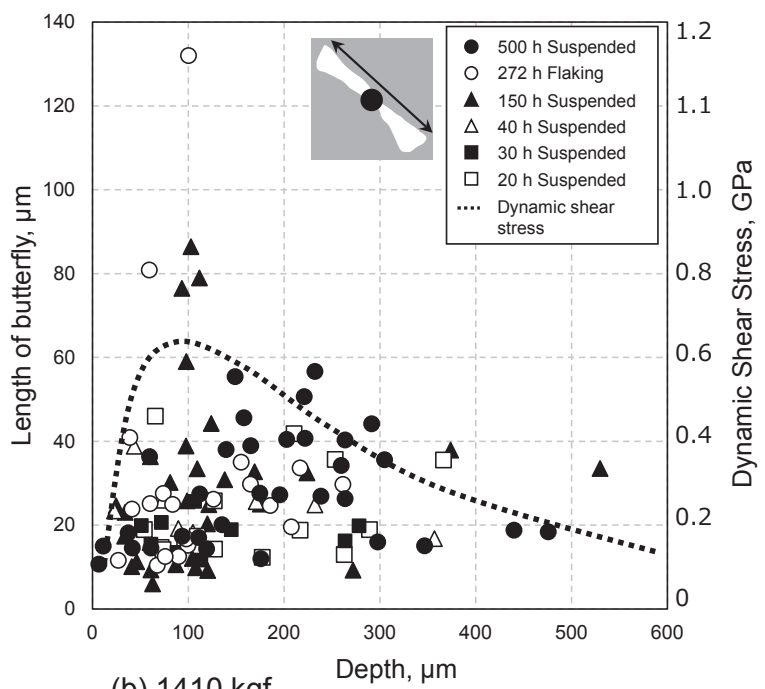

(b) $1410 \mathrm{kgf}$

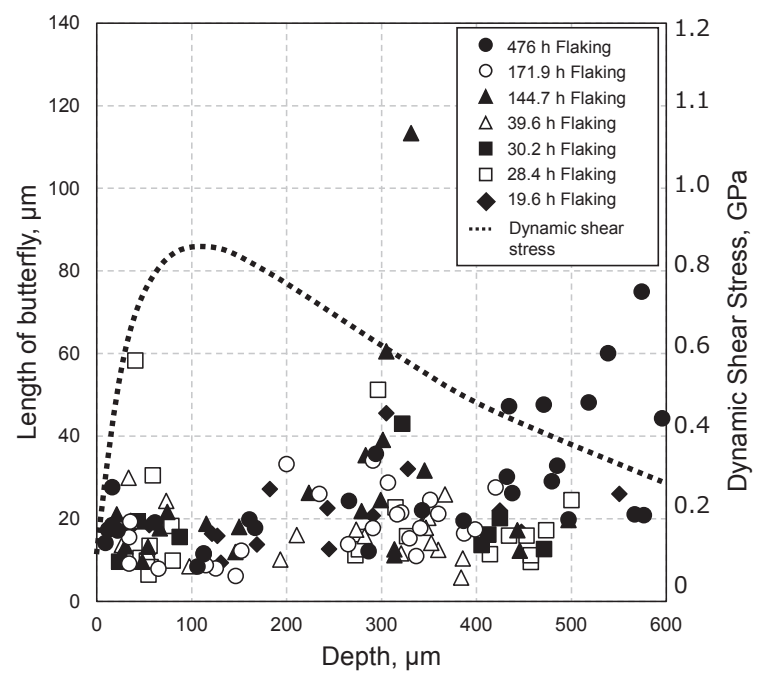

microstructural observations are made by OM and SEM.

Figure 3 shows the images of microstructure obtained

Fig. 2. Distribution of length of the butterfly structure formed along the depth in the inner ring of a 6206 deep groove ball bearing with hardness of $735 \mathrm{HV}$ under RCF testing load of (a) $635 \mathrm{kgf}$ and (b) $1410 \mathrm{kgf}$.

by the OM of $735 \mathrm{HV}$ specimen after the RCF life test with the load of $635 \mathrm{kgf}$ and $1410 \mathrm{kgf}$ for $20 \mathrm{~h}$ and 19.6 $\mathrm{h}$, respectively. The top part of microstructure shows the inner ring raceway surface, whereas the subsurface region of microstructure with loading of $1410 \mathrm{kgf}$ shows a darker contrast region known as a Dark Etching Constituent (DEC). The DEC extends from 50 to $300 \mu \mathrm{m}$ depth from the surface. This is fatigued structure which indicates the presence of higher dynamic shear stress in the subsurface region [5].

Figure 4 shows the image of a microstructure obtained from the SEM of the DEC region shown in fig 3(b). The microstructure has slip-bands in a ferrite grain. Similar slip-bands were also found in the microstructure of the bearing specimen tested up to $500 \mathrm{~h}$ for the same test load.

Furthermore, the frequency of the butterfly structure was lower at the depth of $250 \mu \mathrm{m}$, as shown in fig. 1(b). (a) $635 \mathrm{kgf}$

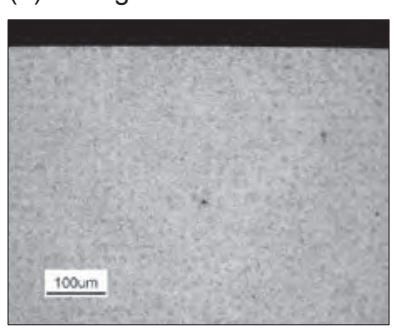

(b) $1410 \mathrm{kgf}$

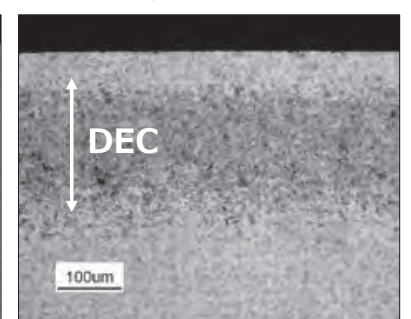

This part was observed by OM in the specimen which is $\mathrm{RCF}$ tested up to $476 \mathrm{~h}$ as shown in fig. 5. A large number of

White Etching Constituent (WEC) was observed at this Fig. 3. Microstructure of $735 \mathrm{HV}$ specimen after RCF test for (a) $20 \mathrm{~h}$ at $635 \mathrm{kgf}$ and (b) $19.6 \mathrm{~h}$ at $1410 \mathrm{kgf}$ observed by optical microscopy. The DEC corresponds to the Dark Etching Constituent formed at subsurface region.

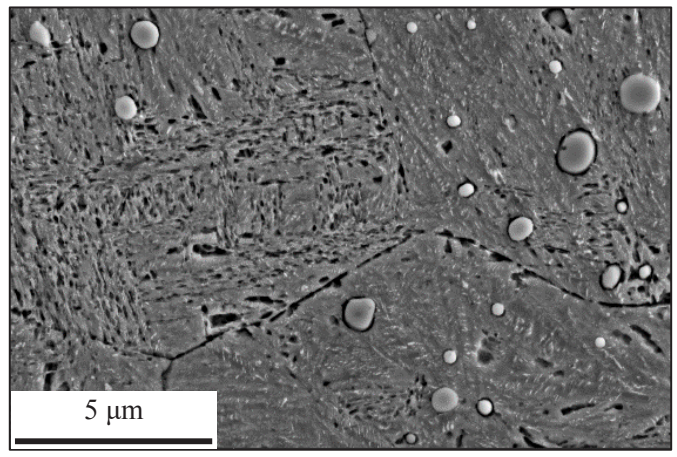

Fig.4. Microstructure of specimen after RCF test for $19.6 \mathrm{~h}$ at $1410 \mathrm{kgf}$ observed by SEM. The microstructure corresponds to the DEC region formed at the subsurface.

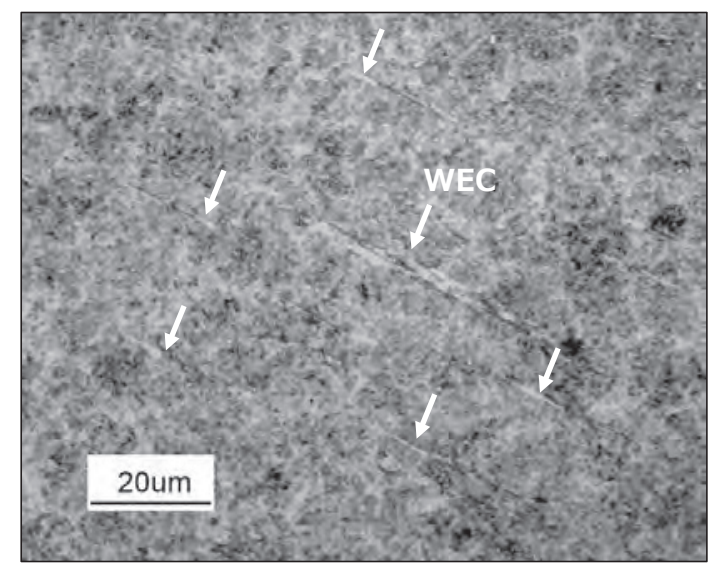

Fig. 5. Microstructure of $735 \mathrm{HV}$ specimen after RCF test for $476 \mathrm{~h}$ at $1410 \mathrm{kgf}$ observed by OM. The WEC corresponds to White Etching Constituent formed at subsurface region.

depth. It has been reported that the WEC structures are developed with in the DEC region [6] and the depth of $250 \mu \mathrm{m}$ is the most developed microstructure area in this test condition of $1410 \mathrm{kgf}$ test load. 
A detailed quantitative analysis is done by EBSD/OIM to evaluate the microstructures in the region nearby of to a butterfly structure. Figure 6 shows the IPF and IQ map of $735 \mathrm{HV}$ specimen after the RCF test for $20 \mathrm{~h}$ with 635 kgf test load. Fig. 6(a) and fig. 6(b) shows the butterfly structure formed nearby to an inclusion at the depth of $150 \mu \mathrm{m}$ which belong to a subsurface region. The IPF map shows the color that indicates the grain orientation. The inside of butterfly structure was not indexed by
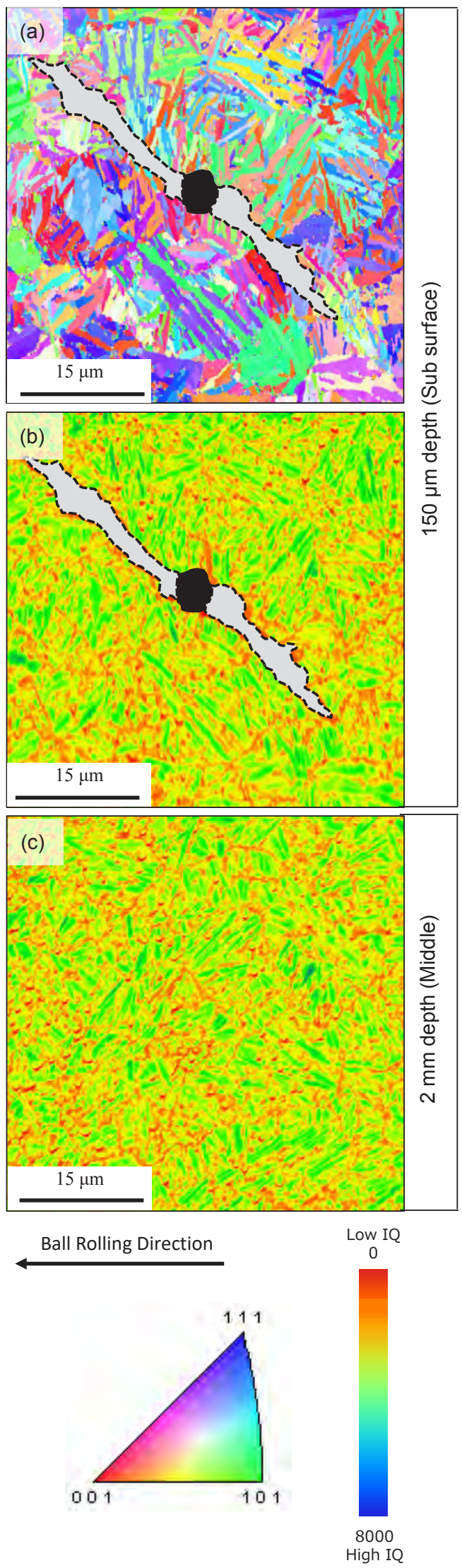

\section{EBSD due}

Fig. 6. The subsurface region IPF and IQ map shown at (a) and (b) respectively are for $735 \mathrm{HV}$ specimen tested for $20 \mathrm{~h}$ at $635 \mathrm{kgf}$. The middle region IQ Map shown at (c) is for specimen tested for $19.6 \mathrm{~h}$ at $1410 \mathrm{kgf}$ for reference.

to the nanocrystalline ferrite structure. There was a lack of sufficient data from these regions and therefore, it is highlighted by the gray area surrounded by dotted lines. The inclusion is highlighted with black color.

A method for visualizing the strain was established using the IQ values obtained from the EBSD/OIM analysis. The lower IQ value is caused by poor crystallinity, which corresponds to high strain expressed as red color, similarly, a higher IQ value corresponds to the lower strain expressed as blue color. Fig.6 (c) is the IQ map for $735 \mathrm{HV}$ specimen at the depth of $2 \mathrm{~mm}$ which belong to an unfatigued region after the RCF test. The IQ map has green-yellow colored regions because of the presence of an initial strain in microstructure, which is generated during the heat treatment process with phase transformation.

In fig. 6(a), the lath microstructure outside the butterfly region was maintained even after RCF test. This also well corresponds to fig. 3 (a) where there is a no change of contrast in the subsurface region. The IQ distribution of the undeformed area in fig. 6(b) is also homogeneous, which is shown by the uniform greenyellow color distribution over the map. However, the stress field around the inclusion is symmetric according to the elastic stress theory, which doesn't match with the shape of butterfly structure which has wings inclined at $45^{\circ}$ against to the rolling direction.

Moreover, it has been reported that the butterfly wing consists of nano-crystalline ferrite formed by the severe plastic deformation of the neighboring region of an inclusion [3]. The mechanism of the direction of butterfly wing has not been explained yet, but these results reconfirm that formation of butterfly is resulted from significant strain localization by stress concentration under RCF load.

Figure 7 shows the IPF and IQ map of $735 \mathrm{HV}$ specimen after RCF test for $150 \mathrm{~h}$ at $1410 \mathrm{kgf}$. The observation was done at the depth of $101 \mu \mathrm{m}$ which belong to a subsurface region. The figure shows a smaller

butterfly structure nearby an inclusion as shown in fig. 2(b). Fig. 7(a), is an IPF map which shows that the surrounding lath microstructure is collapsed due to deformation. This also well corresponds to the subsurface DEC region, which shows a darker contrast in fig. 3 (b) and the slip-bands in fig. 4. Fig. 7(b) is an IQ map which shows a wide region of red color which belongs to the lower IQ value from a higher strain, distributed over the deformed microstructure.

From these results, it is suggested that the accumulation of strain in the neighboring region around the inclusion suppresses the formation of the butterfly structure.

\subsection{Influence of the soft microstructure on the butterfly structure formation and bearing life}


The previous section showed that the formation of butterfly structure can be suppressed through the elimination of the strain localization by increasing the RCF stress. This section investigates the effect of soft microstructure on the strain localization and butterfly structure formation. The soft microstructure has a
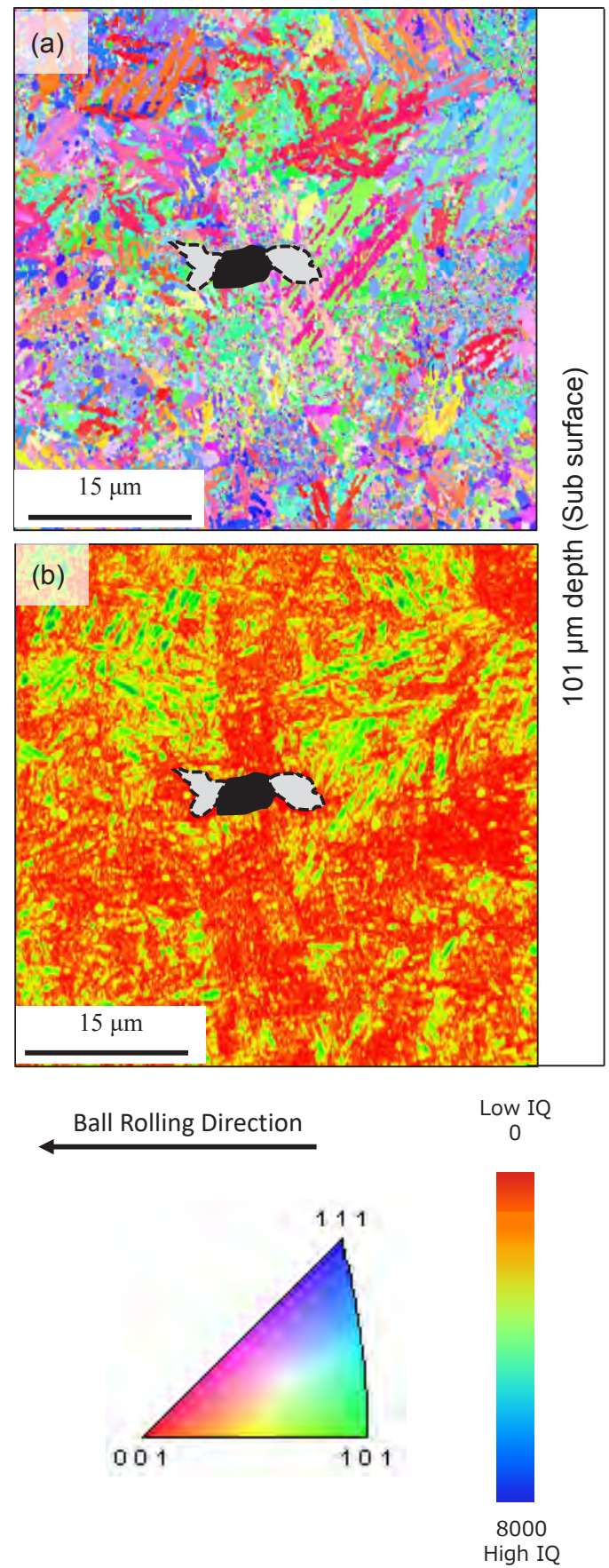

Fig. 7. The subsurface region IPF and IQ map shown at (a) and (b) respectively are for $735 \mathrm{HV}$ specimen tested for $19.6 \mathrm{~h}$ at $1410 \mathrm{kgf}$.

relatively low hardness of $600 \mathrm{HV}$ which is obtained by tempering.

Figure 8 shows the frequency distribution of butterfly structures along the depth of the inner ring of $600 \mathrm{HV}$ specimen. The radial test load of $1410 \mathrm{kgf}$ was applied for the RCF life test. The number of butterfly structures was measured at various depths from the raceway surface with $50 \mu \mathrm{m}$ apart. The calculated dynamic shear stress was almost similar in the case of $600 \mathrm{HV}$ and 735 HV for same radial load of $1410 \mathrm{kgf}$ (fig. 1 (b)). The frequency of butterfly structure was relatively small. Almost, no butterfly structures were observed at the depth of maximum dynamic shear stress, even when the after the

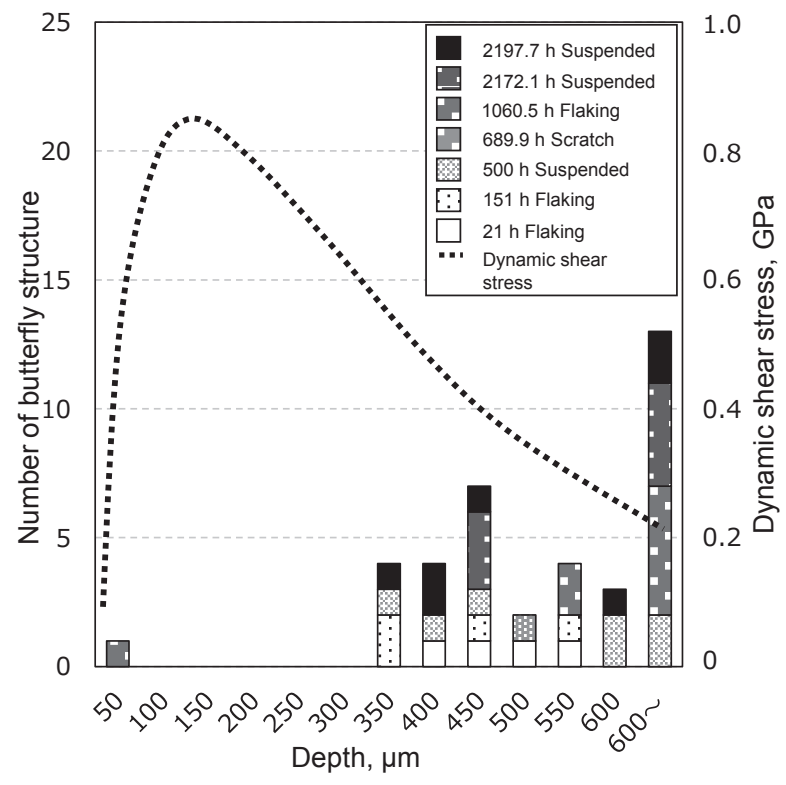

Fig. 8. Frequency distribution of the butterfly structure formed along the depth in the inner ring of a 6206 deep groove ball bearing with hardness of $600 \mathrm{HV}$ under the load of $1410 \mathrm{kgf}$.

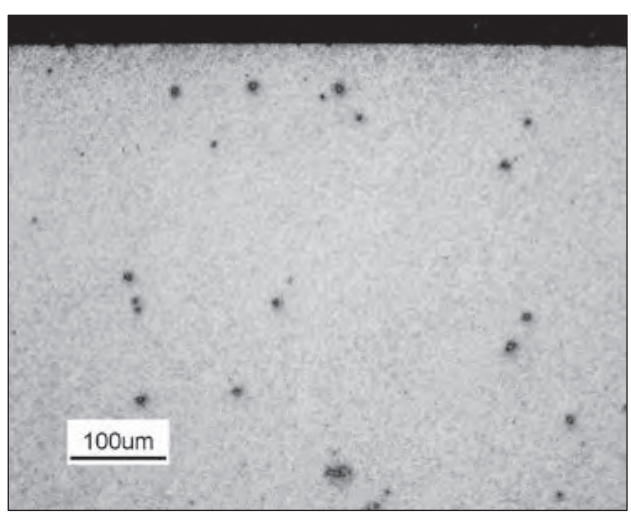

Fig. 9. Microstructure of specimen after bearing test for 20.8 $\mathrm{h}$ at $1410 \mathrm{kgf}$ observed through OM.

observation area was increased for various cross-section. On the contrary, the frequency of butterfly structure was higher in the depth below $350 \mu \mathrm{m}$.

Figure 9 shows the OM image of the $600 \mathrm{HV}$ specimen $\mathrm{RCF}$ test at $1410 \mathrm{kgf}$ for $20.8 \mathrm{~h}$. Unlike $735 \mathrm{HV}$ specimen, there was no DEC observed in the fatigued microstructure at subsurface region. This effect can be attributed to the difference of microstructure between $600 \mathrm{HV}$ and $735 \mathrm{HV}$ specimen. In order to show the amount of deformation in $600 \mathrm{HV}$ specimen, a hardness measurement was done along its depth.

Figure 10 shows the hardness distribution along the depth of this $600 \mathrm{HV}$ specimen. The hardness variation well corresponds to the shear stress distribution and the 
high hardness region is from 50-400 $\mu \mathrm{m}$ which doesn't has any butterfly structures as shown in fig. 8 .

To further investigate this reduction of butterfly structure at subsurface region, the microstructure was evaluated by EBSD / OIM analysis.

Figure 11 shows the IQ maps of the subsurface region of $600 \mathrm{HV}$ and $735 \mathrm{HV}$ specimen tested at $1410 \mathrm{kgf}$.

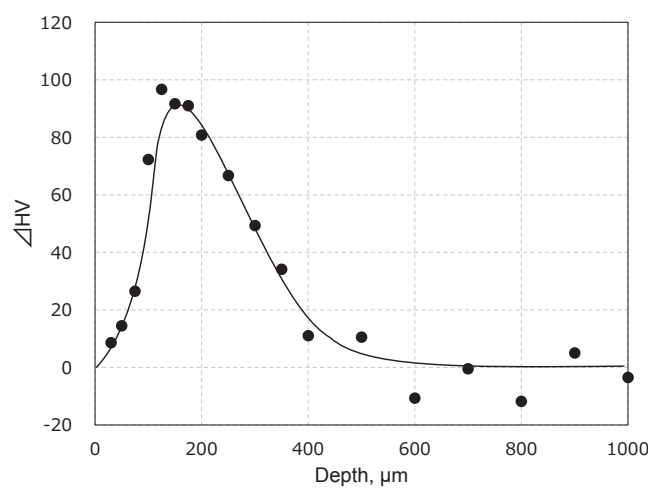

Fig. 10. The amount of change of the hardness at the each depth from the raceway of inner ring for $600 \mathrm{HV}$ specimen after RCF test in the test load $1410 \mathrm{kgf}$.

In case of $600 \mathrm{HV}$ specimen, butterfly structures were absent around the inclusion in these subsurface regions (54 $\mu \mathrm{m}, 118 \mu \mathrm{m}$ and $223 \mu \mathrm{m}$ depth). Moreover, the surrounding area has a uniformly distributed lower IQ value shown by red color, this indicates the homogenous strain distribution in the microstructure in comparison of $735 \mathrm{HV}$ specimen.

The strain is widely distributed all over the subsurface region of softer microstructure which eliminate the formation of the butterfly structure up to the depth of $350 \mu \mathrm{m}$, as shown in fig. 8 . This clearly shows that the homogenous strain distribution inhibit the formation of the butterfly structure near the inclusion.
Fig.12. Weibull plot for estimating the RCF life of $600 \mathrm{HV}$ and $735 \mathrm{HV}$ specimens with the test load of $1410 \mathrm{kgf}$.

In order to confirm the effect of reduction in the butterfly

structure on improving the bearing life, a life evaluation RCF test was done on $600 \mathrm{HV}$ and $735 \mathrm{HV}$ specimen.

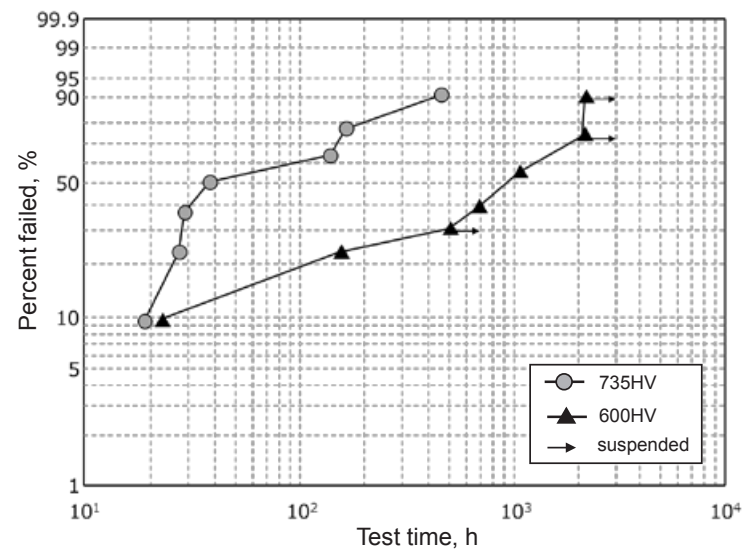

Figure 12 shows a Weibull plot for estimating the RCF life of $600 \mathrm{HV}$ and $735 \mathrm{HV}$ specimen with the test load of

$1410 \mathrm{kgf}$. The Weibull plots show a similar $\mathrm{L}_{10}$ life, but a longer $\mathrm{L}_{50}$ life for $600 \mathrm{HV}$ specimen. Both the specimen has a similar distribution of inclusion since they were prepared from same material ingot. Therefore, the reason for the $\mathrm{L}_{50}$ life improvement can be explained by the reduction of butterfly structure formation in the subsurface region as shown in fig. 8 .

On the other hand, there was not a significant improvement of the $\mathrm{L}_{10}$ life. It was revealed that there are many surface cracks originated near the surface inclusions by SEM observation in RCF tested specimens
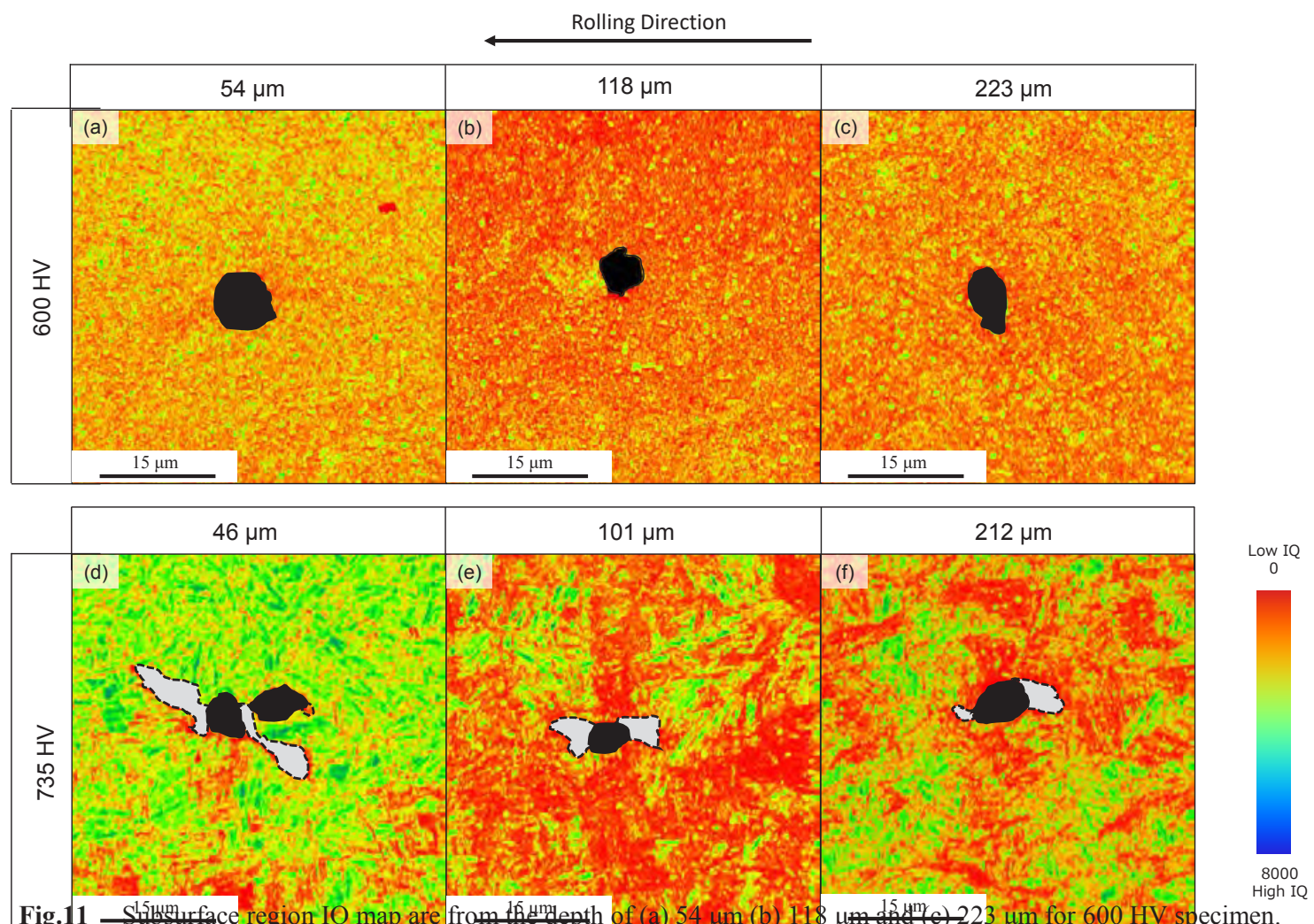

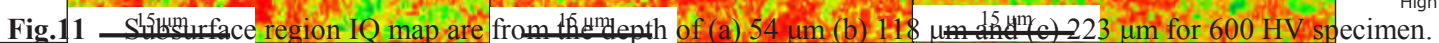
Subsurface region IQ map are from the depth of (d) $46 \mu \mathrm{m}$ (e) $101 \mu \mathrm{m}$ and (f) $212 \mu \mathrm{m}$ for of $735 \mathrm{HV}$ specimen. The test load is $1410 \mathrm{kgf}$. The IQ maps are obtained from the OIM/EBSD analysis. 
with flaking around $\mathrm{L}_{10}$ life. These results suggest that it is difficult to improve $\mathrm{L}_{10}$ life by reducing the formation of butterfly structure, because the initiation of crack from surface inclusion does not need the formation of the butterfly structure.

\section{Conclusions}

The formation of butterfly structure near the inclusion was evaluated from the viewpoint of strain distribution. The following conclusion were obtained.

1. The formation of butterfly structure depends on stress concentration around inclusion. However, this is also depends on deformation of neighboring microstructure around inclusion, which resulted from highly applied stress and reduction of hardness.

2. EBSD / OIM analysis is useful technique for evaluating damage of microstructure due to $\mathrm{RCF}$ in bearing. It is reveals that homogeneous strain distribution in the neighboring microstructure around the inclusion suppresses formation of butterfly structure.

3. The bearing life due to subsurface flaking shows an improvement by homogeneous strain distribution in the neighbouring microstructure around the inclusion.

\section{References}

1. M.H.Evans, PhD Thesis (nCATS, University of Southampton, 2013)

2. K. Sugino, K. Miyamoto, M. Nagumo, K. Aoki, ISIJ Int., 10 (1970) 98-111.

3. A. Grabulov and H. W. Zandbergen, VHCF-4 Conference (University of Michigan, 2007)

4. R. H. Vegter and J.T. Slycke, Journal of ASTM International, 7, 2 (2010)

5. J. Gegner, Tribology-Lubricants and Lubrication (2011)

6. N. Mitamura, H. Hidaka and S. Takaki, Material Sicence Forum (Thermec'2007), 539-543, 42554260 (2007) 